\title{
"Escrevo para que meu povo não morra mais nas mãos da polícia": entrevista com Dinha
}

\author{
Por Graziele Frederico, ${ }^{1}$ Lúcia Tormin Mollo ${ }^{2}$ e Paula Queiroz Dutra ${ }^{3}$
}

Dinha (pseudônimo de Maria Nilda de Carvalho Mota) nasceu na cidade de Milagres, Ceará, em1978. Mudou-se para São Paulo, trazida pela família no ano seguinte. Em 1999 participou da fundação da Posse Poder e Revolução - grupo de pessoas, ligadas ao movimento hip-hop, dispostas a realizar intervenções políticas e culturais em suas comunidades. No mesmo ano iniciou o curso de Letras na Faculdade de Filosofia, Letras e Ciências Humanas da Universidade de São Paulo. Atualmente é doutoranda da área de Estudos Comparados de Literaturas de Língua Portuguesa, leciona na rede pública municipal de ensino, é autora dos livros De passagem mas não a passeio (2008), Onde escondemos o ouro (2013) e Zero a zero - quinze poemas contra o genocídio da população negra (2015). Dinha é também integrante fundadora do selo independente Edições Me Parió Revolução.

\section{Qual a sua relação com a literatura?}

Às vezes eu acho que a literatura na minha vida - e a luta por ter acesso a ela - foi algo genético. Nem preciso dizer que tenho a certeza de que não... somos seres sociais, ora! Minha mãe, nordestina e pobre (em um tempo em que escolas públicas eram para ricos), teve que pagar professora particular para aprender o " $\mathrm{ABC}$ ", pois minha avó a proibira, com medo de que ela usasse as habilidades de leitura para melhor arranjar namoros. Quando aprendeu a ler, minha mãe se escondia debaixo de goiabeiras, no mato, para poder usufruir dos seus "romances", os cordéis e qualquer outro livro a que tivesse acesso. Estranhamente, quando aprendi e me apaixonei pela leitura, muitas vezes fiz greve de fome, porque minha mãe, preocupada com a subsistência física, me perguntava se eu comeria livros. Eu respondia que sim, por dentro. E de raiva não participava das refeições. Talvez ela tivesse se esquecido de sua própria dificuldade em se dedicar à leitura ou, sabendo

\footnotetext{
${ }^{1}$ Doutoranda em Literatura na Universidade de Brasília (UnB), Brasília, DF, Brasil. E-mail: grafrederico@gmail.com

${ }_{2}^{2}$ Doutoranda em Literatura na Universidade de Brasília (UnB), Brasília, DF, Brasil. E-mail: 1torminmollo@gmail.com

${ }^{3}$ Doutoranda em Literatura na Universidade de Brasília (UnB), Brasília, DF, Brasil. E-mail: qpaulad@gmail.com
} 
que literatura por si só não me garantiria vida melhor que a dela, pegava no meu pé para que aprendesse a lavar melhor a louça. Li tudo o que me caiu nas mãos: bula de remédio, pedaços de jornal, poemas impressos em notas de cruzeiros. Depois, ao entrar na adolescência, sem nenhuma privacidade, pois minha casa era um barraco de dois cômodos que sempre abrigou mais de doze pessoas, precisei criar alguma estratégia para encontrar privacidade sem ter que me esconder fora de casa. Então percebi que escrever um diário poderia ser uma forma de manter alguma individualidade. Sem dinheiro, improvisei: descobri que qualquer papel me servia, pois descobria a chave das palavras e as trancava em metáforas, metonímias, alegorias e tudo o mais que pudesse expressar meus sentimentos sem revelar fatos, segredos de menina. Foi assim que comecei a escrever. Para poder existir como indivíduo. Depois, quando me percebi como parte de um coletivo novamente (o aumento da empatia pela família, pela comunidade, pela classe pobre e preta), passei a escrever para corromper as estatísticas, para apontar caminhos, questionar e manter a sanidade mental em um cotidiano miserável e genocida. Escrevo para que meu povo não morra mais nas mãos da polícia (braço armado da elite), para que possamos nos libertar dos cárceres, das novas formas de escravização de nosso povo. Às vezes, escrevo para tentar ressuscitar meus meninos - aquelas pessoas queridas que vi nascer, (sobre)viver e, por fim, serem devoradas pelo Estado.

\section{Você acha importante se dizer autora negra dentro do campo literário brasileiro? O rótulo demarca ou aprisiona sua trajetória?}

Acho extremamente importante me autoafirmar negra e periférica. $\mathrm{O}$ rótulo demarca - e acho isso importante. Quanto a aprisionar. Até pode ser, mas já disse em outros momentos: se o meu rótulo é feminino, negro e periférico (pobre), o de Monteiro Lobato, por exemplo, é branco, masculino, classe média/rica, heterossexual e "normal/universal/clássico". Obrigada. Prefiro os meus. Não ligo a mínima se me enquadrarem aqui ou ali, desde que esses lugares representem os valores da minha classe, da luta contra a sociedade de classes.

\section{O racismo presente na sociedade brasileira afeta a sua produção?}

Sim. Afeta. Eu, quando criança, sofri preconceitos diversos: por morar na favela, por manter um sotaque nordestino, por não ter cabelos lisos. 
Mas nada disso chega perto do que minhas filhas passam e passarão por terem a pele escura e os cabelos crespos. Nada, nada chega perto dos meninos que vi morrer, que vi matarem por serem pretos. Também o que vivi não é nada em relação ao que vivem minhas companheiras de pele mais escura. A gente sabe... o racismo é estrutural e estruturante... minha poética não poderia nunca permanecer imune e, cada vez mais, me esforço para escrever poemas que, para além da força estética, informem, comuniquem, convoquem e incitem a rebeldia contra o racismo e outras formas de opressão das quais o Capital se serve para nos manter subjugadas.

\section{Quais temas ultimamente te interessam, te instigam a escrever?}

Em geral, as imagens (das pessoas, das ruas, dos gestos) vão se acumulando dentro de mim até formarem um bolo na garganta. Só despois é que se destrincham em ritmos e sonoridades. Em geral, os temas passam por quem fui, por quem sou e por quem eu ainda desejo ser. Assim, me interessa o combate ao genocídio do povo negro, o empoderamento de mulheres e a luta contra o feminicídio, além das pessoas que comigo compartilham transportes lotados - sugestivamente apelidados de "cargueiros" pelos motoristas das lotações paulistanas -, e o amor. Esse último é um tema que me desafia e sempre me desafiou. Poemas de amor não são ridículos... são difíceis...

\section{Qual relação de sua escrita com suas experiências?}

Minha escrita é indissociável da minha vida e das minhas condições de classe, gênero, raça, moradia e geração. O hip-hop, por exemplo, é um elemento específico da minha geração que, mais do que servir como fonte de inspiração poética, nos educou quanto à nossa negritude, nos iniciou no movimento negro: as "Posses" agregavam uma juventude rebelde com causa, talentosa, extremamente vulnerável e disposta a lutar contra as tiranias do sistema capital. Fora isso, eu "já disse que não sou outra coisa que não nós/ O que são eles sou / o que sou eu somos elas”.

\section{Qual o peso que o machismo ainda tem no Brasil atual?}

O machismo no Brasil atual ainda tem o mesmo peso de quando minha mãe foi impedida de apender a ler. Avançamos em educação 
(estudamos mais que os homens, em geral), mas avançou o número de mortes de mulheres apenas por serem mulheres. O capitalismo é contraditório. As minissaias que muitas de nós usamos, não raro, têm a mesma função que as burcas: agradar à opinião masculina (como aquelas pessoas que nunca sairiam de casa sem estarem maquiadas, cabelos em ordem, roupa curta ou, para as ricas, caras e da última moda). Ao mesmo tempo em que se fortaleceram as lutas, fortaleceram-se também os grupos extremistas do outro lado. Para usar um vocabulário mais do hip-hop, poderíamos dizer que hoje lutamos "mano a mina"... no futuro, a luta, e o fortalecimento de um mundo sem machismo, será feito "mana a mano".

\section{É possível desvincular a produção literária de um ato político?}

De jeito nenhum. Por ação ou omissão, estamos sempre praticando atos políticos. Aliás, pensando assim, basta existir para ser, além de um ser social, um ser político. Então, não acredito no conto do "emcimadomurismo". Quem se diz neutro ou neutra está, na verdade, do lado opressor. Por isso mesmo não me incomodo com os rótulos. Eles impõem limites e, você sabe... sem limite não há respeito.

\section{O que o corpo significa em sua produção?}

Especialmente nos meus dois últimos livros esse corpo é o próprio conflito. Nos atos cotidianos de violência e morte, na dúvida entre parir (desagradando ao sinhozin moderno que quer morrer quando engravidamos e saímos de licença maternidade) e abortar (desagradando ao sinhozin de antes que lucrava quanto mais a negrada nascesse, e aos de hoje, receosos de perderem o controle sobre nossos corpos femininos). Os corpos, nos meus poemas, servem à denúncia, mas também à esperança de dias mais humanos. Os poemas "Discursos de Teresa" e "Zero a zero" (do livro Zero a zero), são emblemáticos, nesse sentido.

\section{Qual a importância da literatura num país com tamanhas desigualdades sociais?}

Sou chata e deliberadamente fora de moda. Minha definição de literatura segue uma linha materialista histórica, ainda mais à esquerda do mestre Antonio Candido. Como Walter Benjamin, tendo a distinguir "arte" de 
"propaganda" também no campo literário. Assim, um poema-propaganda pode ser tocante, emocionante e transformador, mas não pode ser contestatório. A literatura, por sua vez, enquanto arte, é basicamente contraideológica (mesmo quando recorre ao mito, à utopia ou qualquer outra estratégia aparentemente "alienada") e a propaganda se diferencia dela por reproduzir as falsas ideias, as ideologias dominantes e opressoras. Considerando dessa forma, a literatura (arte, não a propaganda), tem imenso potencial transformador. Em minha dissertação de mestrado defendi o termo "Lirismo de libertação" como sendo um conjunto de características presentes em determinados autores e autoras africanas e afro-brasileiras que tendem a afirmar sua negritude, reatualizar tradições de origens africanas, colocar os povos oprimidos no épico papel de heróis coletivos e, sobretudo, acreditar no poder da palavra como força capaz de transformar o mundo em algo mais justo, mais digno e livre de opressões. Eu também acredito (sem, assim como eles, dispensar a importância das outras armas menos simbólicas, digamos assim...).

Qual sua análise sobre um aumento dos mais diversos tipos de intolerância (religiosa, de gênero, étnico-racial, social) no país? Vivemos tempos mais violentos?

Para mim, vivemos em guerra desde o início da colonização do nosso território. De lá para cá, inúmeras e vergonhosas barbaridades foram cometidas. Após a abolição, por exemplo, criaram-se meios de conter e mesmo reescravizar nosso povo. O processo é sempre muito parecido: criase a fantasia de um inimigo muito poderoso. Esse inimigo costuma ser retratado como tão violento, cruel e desumano, que sua morte estaria sempre muito bem justificada e aceita. Inimigos poderosos justificam estados de exceção, prisões sem julgamentos, extermínios amplamente aplaudidos nas arenas televisivas. Penso que talvez os tempos não estejam mais violentos, mas as ações e reações menos invisibilizadas pela corrente midiática não hegemônica que se forma através das redes sociais e similares. Como mulher, negra (ainda que de pele clara), pobre, favelada, parideira (com conviç̧ão), não me sinto mais agredida e sim menos silenciada. Vocês sabem, na quebrada o extermínio foi sempre moeda corrente. A violência doméstica transcende classes sociais e o rap machista fortaleceu em massa nossa negritude. Mas quando esses fatos ganham visibilidade, parece que acabaram de explodir. Engano nosso. Essas táticas são usadas há 516 anos em nosso território para manter o macho branco no 
poder. O capitalismo escolhe grupos humanos para os inferiorizar, os desumanizar e, por fim, justificar sua exploração e morte. Em muitas quebradas paulistas, por exemplo, morre-se muito menos (80\%) do que entre os anos de 1980 e 2000. Além disso, os meninos e meninas homossexuais podem vestir o que bem entenderem sem serem espancados ou enxovalhados. As mulheres vítimas de violência doméstica nem precisam chamar a polícia (pouco vale), chamam logo um "disciplina" e, se preciso for, levam para o "debate". As igrejas mais diversas e os centros de umbanda continuam se proliferando por aqui. Mas nesses tempos em que grande parte dos nossos irmãos e irmãs estão encarceradas, sua autoorganização cria um Estado paralelo nas favelas. Violência gratuita não é mais admitida. Quanto ao contexto mais amplo do país, sim, aumentaram os diversos tipos de intolerância: grupos armados de votos de fiéis (votos de crentes de religiões diversas, crentes em políticos, artistas ou esportistas diversos e crentes que conseguirão melhorar a vida elegendo este ou aquele partido) lutam para impor suas vontades (em geral conservadoras e desumanas) e incitam, sim, a população a um aumento da intolerância e da violência. Nesse sentido, vivemos uma cisão: enquanto a favela, na medida de suas possibilidades, pratica a paz, o restante do país fica à mercê da classe política (marionetes que nos desviam do verdadeiro problema: a elite exploradora e burra do nosso país).

É possível vislumbrar uma melhora na inserção no mercado editorial a partir das novas mídias, como as redes sociais?

Melhor inserir-se no mercado editorial é uma possibilidade, sim. Mas eu prefiro ver as novas mídias como possibilidades de libertação (nós fazendo por nós e para nós), não de inserção em um ambiente comercial. Prefiro usar a internet para criar e conhecer e compartilhar conhecimento. Por isso, na Me Parió Revolução, aprendemos a fazer todo o processo de editoração e depois ainda disponibilizamos os e-books, gratuitamente. Nosso objetivo é garantir o acesso. Quanto menos amarras, melhor.

Se fosse possível criar uma imagem do Brasil a partir dos escritores contemporâneos, qual imagem você acha que teríamos?

Olha, a imagem criada por mim seria muito marcada por escritoras negras, periféricas, hip-hoppers, sem destaque para a heteronormatividade. Também teria bastante a presença negra masculina, poucos brancos e brancas, 
poucos indígenas. Bastante diferente da imagem criada pela famigerada Flip. É que eu não leio qualquer coisa, sabe? Só porque as editoras acharam que seria vendável. Então, na minha imagem, a branquitude sai perdendo.

\section{Qual importância da liberdade e da democracia para a literatura?}

Se lembra de mim? Da minha falta de liberdade para me expressar, no seio de uma família pobre, mas hierárquica, matriarcal, mas com regras e condutas machistas? Nos contextos em que a liberdade inexiste ou encontra-se ameaçada, a literatura tende a crescer em sua importância. $\mathrm{O}$ desafio de se dizer o que não pode ser dito e as consequentes punições quando somos pegas elevam nossa inventividade, nossa rebeldia, e (tiros e mais tiros saindo pela culatra) mobilizam, expõem as feridas antes ocultas pela roupagem maneirista e forçam mudanças nem sequer sonhadas por quem tentou fazer da ausência de democracia e liberdade um escudo. Obviamente é mais gostoso escrever sem ter medo da polícia, de perder o emprego ou de apanhar de familiares, mas como já disse o poeta: "em tempos fechados de chuva, / só declaro de amor ao Sol".

\section{Quais autores, pensadores, pessoas têm influência na sua obra?}

Comecei sendo influenciada pelas obras canônicas (do vestibular da Fuvest): João Cabral de Melo Neto, Bandeira, Cora Coralina, Cecília Meirelles, Drummond, Murilo Mendes, Fernando Pessoa, Augusto dos Anjos e Gregório de Matos. Ao mesmo tempo que era influenciada por esses e outros mais, eu percebia um distanciamento terrível entre o que eu lia e o mundo em que eu vivia. Eu era tocada por uma poética que pouco tinha a ver com minhas experiências pessoais: como já disse a Lívia Natália "meu pai [também] não montava a cavalo, não tínhamos nem uma biblioteca pública - que dirá particular -, não tínhamos nem morávamos em fazendas, e até mesmo a comida era minguada. Meu pai saiu de Milagres dizendo que se encontrasse um lugar onde pudesse comer três vezes ao dia, nunca mais pisaria naquela cidade. Apenas João Cabral e Graciliano me faziam chorar, imaginando minha própria família, retirante. Mas, depois, muita coisa mudou. Conheci Carolina, tomei ciência da existência dos Cadernos negros e tive contato com autores que se tornariam uma espécie de núcleo duro do que hoje chamamos de literatura negramarginal-periférica, como Ferréz, Buzo, Allan da Rosa, Cidinha da Silva, Esmeralda Ribeiro, Conceição Evaristo, Geni Guimarães, Elisa Lucinda e 
uma porção de africanos e africanas (Luandino Vieira, Agostinho Neto, Noêmia de Sousa, José Craveirinha, Pepetela, Paulina Chiziane e muito mais). Encontrei nessas autoras e autores o que sentia falta naqueles primeiros: "meu eu". Me encontrei na literatura guerrilheira, carregada dos sofrimentos e dignidades da negritude, do feminino, da favela. Tudo isso somou-se ao velho rap companheiro e fez a minha poesia. 